\title{
ACOTACIONES DEL TRAMPOLÍN: RESPUESTA A ROBERTO VERNENGO
}

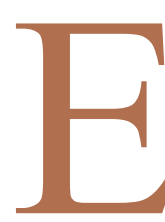

n el mes de febrero de 1989 apareció en la Facultad de Derecho de la Universidad de Buenos Aires un folleto en el que, al lado de otro trabajo, Roberto Vernengo incluía esta misma crítica a mi artículo sobre el concepto de derechos humanos. En una breve presentación Vernengo afirmaba que no pretendía «ejercer la exégesis del pensamiento de nadie» y que tomaba las opiniones de los demás «como trampolín para el texto». Es importante que el lector tenga esto en cuenta para medir y ponderar lo que en el escrito de Vernengo puede ser efectivamente una crítica de mis ideas y lo que es directamente un pensamiento suyo que se limita a tomar como pretexto algunas reflexiones o segmentos de reflexiones mías. Lo que yo pretendo aquí, en mi modesta condición de trampolín, es hacer algunas precisiones que estimo necesarias para situar los desacuerdos en sus justos términos, ayudando así al lector a distinguir claramente el texto y el pretexto.

1. Vernengo parte de unas consideraciones idiomáticas que para mí son perfectamente incomprensibles. La idea de que si fuéramos ingleses o australianos podríamos hablar de derechos morales con toda tranquilidad, pero si somos argentinos o alemanes no podemos hacerlo es, desde luego, sorprendente. Es cierto que «nuestra tradición lingüística y teórica» no ha usado esta expresión, y también es cierto que hay una «larga tradición» anglosajona que la usa en sentido vulgar y también en sentido técnico. Lo que pasa es que ninguna de estas consideraciones puede servir seriamente de base para una argumentación ni a favor ni en contra de la expresión. El argumentum ad antiquitam es una conocida falacia que no lleva a ningún sitio. Lo importante es saber si la idea de «derechos morales» resuelve algunas persistentes aporías de «nuestra tradición lingüística y teórica». $\mathrm{Y}$ yo creo que lo hace con cierta eficacia. Vernengo permanece, en cambio, abrazado a esta tradición. Pero eso, evidentemente, no es ningún razonamiento. Es simplemente un prejuicio. 
2. El equívoco fundamental que introduce Vernengo en su crítica es reinterpretar mi texto como si se tratara de una «propuesta» de «emancipar la idea de derecho moral de sus condicionamientos institucionales o de sus condicionamientos de rol». Para cualquiera que haya leído mi trabajo es evidente que yo no hago tal cosa. Lo que yo afirmo, ya bien entrado mi trabajo, es que si pretendemos hablar de derechos humanos como derechos morales universales, entonces nos vemos obligados a hacer eso. Digo exactamente: «Lo que me interesa ahora es presentar algunas consecuencias que para la noción de derechos humanos en sentido moral tiene el rasgo de 'universalidad' que se predica de ellos.» Y claro, la consecuencia lógica inmediata es que ya no sirve pensar en tales derechos como producto del juego de instituciones o de la adscripción de roles, porque no hay instituciones ni roles de los que participen todos los seres humanos. Por eso afirmo que concebir los derechos humanos universales como derechos morales nos obliga a desvincular la idea de derecho moral «de las instituciones éticas concretas que funcionan en una moralidad positiva o que son propuestas por una moralidad crítica». Esto tiene cierta importancia en relación con puntos de vista muy extendidos en la filosofía moral, que hasta ahora había teorizado los derechos morales como derechos surgidos institucionalmente. Y eso es lo que yo pretendía señalar. Deploro tener que reproducir párrafos que se hallan en la misma página del texto que Vernengo usa de trampolín, pero su omisión a guisa de pretexto produce una gratuita alteración de todo el sentido de mi trabajo. Hasta el punto de que todo aquello es reinterpretado por él como si yo dijera «que un derecho moral es ajeno a un código moral prescriptivo que funciona como una moral concreta, y también es ajeno a los principios ideales que postule una moral crítica»y, desde ahí, por supuesto, Vernengo puede extraer una conclusión facilona: Si un derecho moral es ajeno a la moral positiva y a la moral crítica, entonces, es ajeno a la moral y por tanto no es un derecho moral. Pero, claro, todo esto no tiene nada que ver con mi afirmación de que los derechos morales universales no pueden ser producto de instituciones de una moralidad, sea ésta positiva o crítica, porque, ¿qué hay de los que no participen ni empírica ni idealmente en tales instituciones? ¿No tienen los derechos morales universales?

3. Vernengo coincide conmigo en que la noción de derecho en sentido subjetivo no puede ser entendida al margen de un contexto normativo. Pero aquí acaban las coincidencias. Él parece mantener que la idea de derecho subjetivo equivale prácticamente a la de libertad o facultad. Esto le lleva a sugerir, entre 
otras cosas, que «la ausencia de normas con que se equipara la libertad, puede ser pensada... como la instauración de normas que otorgan autorizaciones». Al margen de la innovadora noción de norma ausente presente, o de norma instaurada no instaurada, yo creo que esto no funciona tampoco por ser excesivamente reductivo. En la noción de «derechos» hay muchas más cosas que puras facultades como libertades. Pero es que, además, Vernengo contempla la inserción de los derechos en contextos normativos como simple reflejo de los deberes. Pues bien, esta teoría del «reflejo», que es, efectivamente, la versión kelseniana de la idea de «correlatividad» entre derechos y deberes, plantea a quien la mantiene una enojosa cuestión: Si los deberes jurídicos «reflejan» a veces derechos legales ¿por qué los deberes morales no «reflejan» nunca derechos morales? ¿Qué misteriosa incapacidad sufren los deberes morales para no poder ser correlatos de derechos morales? Vernengo, naturalmente, tiene que decir que esa dolorosa postración la sufren sólo los deberes morales castellanos pero no los ingleses. Se trataría simplemente de una tara hereditaria de carácter idiomático. Kelsen, por el contrario, siendo mucho más consecuente, acepta que pueda hablarse de derechos morales emanados de las normas de una moralidad positiva. Pero el asunto no para ahí, porque la teoría del «reflejo» tiende a dar al deber una prioridad epistemológica muy discutible. Discutible hasta en el propio Kant, que es en este punto muy oscuro. Que, para Kant, la condición de posibilidad del mundo moral (es decir, del mundo de los deberes) sea la libertad de la voluntad en el «homo noumenon» no deja de dar que pensar. Sobre todo si simultáneamente afirma que el único «derecho innato» es la libertad. Sé que hay otros textos y el asunto es complejo, pero me parece que la preexistencia de los derechos a los deberes no se puede despachar así como así diciendo que es asunto de mejor o peor «sabor ideológico» (aunque es evidente que toda moral autoritaria tiene como cláusula permanente que los destinatarios tienen deberes morales pero no derechos morales).

Identificar los derechos con libertades y explicarlos como reflejos de deberes se conecta con el tema de las categorías de Hohfeld y su posibilidad de ser traducidas a fórmulas lógicas cuyos operadores sean única y exclusivamente «obligatorio», «prohibido» y «permitido». Aquí Vernengo replantea un problema interesante, pero también introduce una confusión. La confusión es que no parece distinguir bien entre la posibilidad de traducir las categorías hohfeldianas a categorías de la «dogmática continental», que es una posibilidad que yo no excluyo (en 
rigor, ni siquiera la menciono), y la posibilidad de traducir dichas categorías a enunciados formados únicamente con las modalidades deónticas clásicas, que es lo que yo cuestiono, salvo por lo que respecta a la «libertad» hohfeldiana. Éste es el problema interesante. Y por lo que yo sé no parece tan resuelto como afirma Vernengo. De hecho las lógicas que se han desarrollado en torno al modelo hohfeldiano no usan los operadores clásicos. Kanger y Lindahl, por ejemplo, proponen dos operadores mucho más versátiles y ambiciosos («It shall be the case...» y «sees to it...», o en la propuesta de Lindahl, «shall» y «do»). Lo que yo sugiero es que si tratamos de traducir las cuatro categorías de Hohfeld a enunciados deónticos formados con los tres operadores clásicos acabamos por hacerlas pivotar en torno a una de las modalidades, que es la de «libertad». Esto estaría de acuerdo con la noción de «derechos» que estipula Vernengo, pero implicaría malversar todas las posibilidades del análisis de Hohfeld. Intuyo, sin mucha convicción, que una salida posible para mantener las cuatro categorías puede ser introducir modalidades deónticas también en las variables lógicas con lo que estaríamos frente a una especie de lógica de «normas (o proposiciones normativas) de segundo orden». Pero esto es una simple intuición que sería necesario contrastar.

4. Admito que decir que los derechos en general (no sólo los derechos humanos) son un componente del sistema normativo (y no sólo del sistema jurídico) que está «antes» o es «anterior» a las normas de comportamiento o de competencia de ese sistema puede ser una manera imprecisa y poco feliz de expresarse, pero no creo que ello pueda ser pretexto para tanto escándalo y conmoción. Desde luego dicha expresión no significa que exista algo extraño e incognoscible suspendido sobre el sistema normativo en una especie de aire metafísico. Quiere decir poco más o menos lo mismo que cuando, hablando por ejemplo de un silogismo, se dice que las premisas están «antes» o son «anteriores» a la conclusión. $\mathrm{O}$ cuando se dice que en un diálogo la pregunta es «anterior» a la respuesta. Nunca pretendí yo con esa manera quizás desafortunada de expresarme remover las cenizas del viejo fisicalismo o dar pie a una nueva refriega antimetafísica. Lo que quise transmitir es, en resumen, lo siguiente: Los derechos tienen, a mi juicio, un componente predominante que es un estado de cosas al que se considera un bien, un objetivo que se trata de perseguir, una meta a la que llegar, etc..., todo ello en virtud del sistema normativo en que se inscriben. En el plano individual, cuando un estado de cosas es considerado bueno, o se piensa en un objetivo o una meta como algo valioso, entonces 
se tienen «razones» para hacer o dejar de hacer ciertas cosas. Que uno tenga «razones» no quiere decir, desde luego, que las «razones» sean algo así como objetos que se puedan poseer o de los que se pueda decir: ¡«Mira, ahí va una razón»! Y menos, naturalmente, la trivial simpleza de que son algo que «inventó» el «autor israelita» Joseph Raz. Lo que sucede, y sucede todos los días, es que entre un objetivo o meta o estado de cosas que se desea y las acciones de los seres humanos se establece una cierta relación de acuerdo con la cual se hace referencia a esos objetivos y metas para justificar estas acciones. A eso se le llama «dar razones» de mis acciones o «tener razones» para actuar de un cierto modo. Pues bien, en el ámbito de los sistemas normativos complejos también se da esto. Se establecen como valiosos, buenos o deseables ciertos estados de cosas y se apela expresa o tácitamente a ellos para justificar la imposición de normas de conducta o la atribución de normas de competencia. Esos estados de cosas, objetivos o metas operan como «razones» que justifican dichas normas. Y esa, junto al rasgo de «Individuación del bien», me parece ser a mí la estructura básica de la noción de «derecho» (y, por ende, de la noción de «derecho humano»). Y por eso afirmo que tales normas de conducta o competencia no definen el derecho, como se ha pretendido. Lo que define al derecho es el estado de cosas, meta u objetivo valioso que el sistema propone como razón, justificación, sentido, etc..., de ese conjunto de normas de conducta o competencia. Si esto es aceptable, se puede decir sin mayores problemas que el núcleo definitorio de los derechos es «anterior» a las normas y que éstas son «posteriores» a él, pues aquél es el primer estadio de una secuencia argumental y éstas parecen ser estadios ulteriores.

Si todo esto se tiene en cuenta (aunque se discuta profusamente) se comprenderá que afirme que ese razonamiento o secuencia argumental «no puede ser aprehendido en los lazos formales del razonamiento lógico-deductivo». Lo que ello quiere decir es simplemente que no creo que utilizando como únicas premisas enunciados sobre la bondad o deseabilidad de estados de cosas puedan obtenerse deductivamente conclusiones en forma de normas de conducta o de competencia. Esto, como es obvio, tiene poco que ver con el viejo tema del valor de verdad de los enunciados normativos y su relación con la posibilidad de una lógica de normas. Es otro problema.

5. Por lo dicho aquí y en mi trabajo supongo que todo el mundo comprenderá que cuando Vernengo encuentra en mi texto «valores» y «bienes» como «entidades» u objetos característicos de una «ideología irracional», «entes notoriamente metafísicos» 
que «dan sentido y justificación a la realidad», su hallazgo es meramente imaginario. En este caso, desde luego, la cabriola no tiene nada que ver con el trampolín. Decir que en los sistemas normativos podemos encontrar descripciones, definiciones, valoraciones, principios, enunciados teleológicos, reglas técnicas, etc... que son «entidades» (lingüísticas, se entiende) que no son normas es algo perfectamente comprensible y nada problemático. Quizás haya cometido el severo delito de llamar a todo eso «entidades», pero otros delitos no los he cometido. No he afirmado en parte alguna que «den sentido y justifiquen a la realidad social»; ni he sugerido en ningún lado que sean «objetos» con vida independiente, ni nada que se le parezca. Se puede, creo, hablar de cosas valiosas, de bienes, de estados de cosas buenas sin incurrir en graves pecados metafísicos. Incluso hasta puede haber una lógica de esos enunciados. Rescher o von Wright han escrito muchas páginas sobre valor o bondad sin caer, que yo sepa, en el proceloso mar de las ideologías irracionales. Y también creo que se puede hablar de que tales cosas tienen «fuerza» sin suponer apresuradamente que son algo así como fuentes de energía. Los bienes, las valoraciones, las preferencias, las metas se suelen presentar, tanto en los planes de vida como en los sistemas normativos, en estructuras estratificadas y es de lo más usual decir que aquellos que ocupan estratos superiores tienen «más fuerza» que los que ocupan estratos inferiores. Emparentar estas cosas con oscuridades nietzscheanas o entes leibnizianos es realmente creativo, pero yo no tengo nada que ver con ese alarde de imaginación.

6. Vernengo supone, con algunos otros autores, que hablar de derechos en el terreno de la moral le arroja a uno irremediablemente en brazos del iusnaturalismo. Dejando a un lado lo molesto que ha de ser para los angloparlantes tener que ser iusnaturalistas desde pequeñitos, lo cierto es que esa especie de conexión necesaria entre derechos morales y iusnaturalismo no parece advertirse por ningún lado. Igual que no se advierte tampoco que haya razón alguna para mantener la terca vinculación entre derechos y derecho positivo. Vernengo mantiene que la «noción de right o derecho subjetivo no es una categoría formal, sino es una construcción conceptual elaborada a partir del supuesto de la existencia de ciertos conjuntos de normas, mediante la cual pensamos instituciones contingentes que pueden darse en los derechos positivos». Esto es harto discutible, pues supone situar la noción de derecho subjetivo en el lenguaje o metalenguaje de la ciencia o la filosofía del derecho como una herramienta para «pensar» datos del lenguaje jurídico, y ello implica 
que cuando este lenguaje jurídico adscribe derechos no está funcionando normativamente, sino «pensativamente», lo que es ciertamente poco convincente. Pero en todo caso no se advierte por qué no podemos elaborar una «construcción conceptual» idéntica a partir del supuesto de la existencia de conjuntos de normas morales con objeto de pensar instituciones contingentes que puedan darse en la moralidad positiva, o en una moralidad crítica que eventualmente se nos pueda ocurrir diseñar. Si Vernengo no permanece varado en una simple obcecación idiomática lo único que se me ocurre que puede alegar para rechazar tal posibilidad es que no puede darse el supuesto de que existan conjuntos de normas morales o que no podemos pensar en instituciones morales. Creo que Vernengo sugiere efectivamente esta última imposibilidad. Supongo que él identifica la idea de «institución» con ciertas agencias jurídicas de protección coactiva, con cargos remunerados, reglamentos internos, etc..., es decir, con instituciones jurídico-políticas. Cuando habla, por ejemplo, de la pérdida de soporte institucional de la «Iglesia romana» al perder poder político, creo que presupone esa identificación. Y por eso puede afirmar que no se dan sistemas morales de protección de esos presuntos derechos morales. Pero esto, como es obvio, no se corresponde con la realidad. Hay instituciones económicas, sociales y morales al margen del ordenamiento jurídico positivo. La amistad, por ejemplo, o el mercado paralelo del dólar.

7. La segunda parte de mi trabajo versa sobre las consecuencias implícitas en las características formales que se predican usualmente de la idea de derechos humanos. Digo así: «Voy a tratar de analizar las más típicas características formales que se suelen adscribir a ellos en el lenguaje ético, jurídico y político sobre el telón de fondo de la idea genérica de 'tener un derecho' que antes he ofrecido». Y acto seguido trato de presentar los problemas y las conclusiones más o menos difíciles y contraintuitivas que se tendrían que inferir de aquellos rasgos formales. Pues, bien, es aquí, principalmente, donde Vernengo, situándose de un salto al margen de mi argumentación, dispone profusamente de algunos retazos de mi trabajo convenientemente sacados de su contexto, reelabora otros y procede después a refutarlos ingeniosamente. He aquí algunas muestras de sus ocurrencias. Me atribuye la afirmación de que esos rasgos formales -universalidad, carácter absoluto, inalienabilidad«corresponderían analíticamente a la idea genérica de 'tener un derecho'». Me atribuye también la pretensión de hacer el análisis de esos rasgos «como explicación justificatoria de la supuesta necesidad empírica y conceptual de los derechos postulados». Además me atribuye la 
sugerencia de que dichos rasgos pueden ser predicados de constantes lógicas, como son los operadores deónticos. Me atribuye además la «tesis paradójica» de que hay algún derecho que es una obligación. Me atribuye también que mis consideraciones sobre las implicaciones de su pretendido carácter absoluto se refieren a su fundamentación. Me atribuye, más en general, la pretensión de hacer un ensayo de fundamentación moral de los derechos humanos. Me atribuye después el ser renuente a su fundamentación moral. Y ya en el colmo de la fantasía llega hasta a sugerir que trato de imponer obligaciones a los sistemas jurídicos, que tengo cierta oscura complicidad con los derechos de los propietarios y que me identifico de algún modo con el iusnaturalismo del siglo XVII. Como quiera que, al menos en Buenos Aires, el amable lector estaba desde el principio avisado de que Vernengo no quería «ejercer la exégesis del pensamiento de nadie», estas y otras piruetas no le serán regateadas a su legítimo autor.

8. Aunque se parece algo más a una argumentación crítica, tampoco es pertinente la objeción de Vernengo contra mi afirmación de que, dado que la vinculación entre un derecho humano universal y un sistema de derecho positivo resulta problemática, «parece menos controvertible que ubiquemos a los derechos humanos en el ámbito de la ética, como derechos morales y no como derechos legales». Y no es tampoco pertinente porque mi texto, olvidado por Vernengo, sigue así: «Esto, naturalmente, plantea a su vez un conjunto de problemas propios relativos a la dicotomía moralidad positiva/moralidad crítica, pero no voy a ocuparme de ellos aquí». Sin tener esto en cuenta pasa Vernengo sin más a contraargumentar: igual que no hay un derecho positivo universal -dice- tampoco hay una moralidad positiva universal, «y menos ciertamente una única moralidad crítica». Aunque, como queda dicho, no me ocupaba de ello, quiero señalar aquí, sin embargo, la razón de esa ubicación: Mientras que no conozco ningún sistema de derecho positivo que pretenda que sus normas sean universalmente aplicables, creo que toda moralidad positiva funciona internamente como si sus normas fueran de aplicación universal, y toda moralidad crítica lleva consigo, casi por definición, una pretensión equivalente. Esto fue lo que me indujo a afirmar que si los derechos humanos han de ser universales tienen en el ámbito de la ética una ubicación «menos controvertible».

9. A consecuencia de los graves pecados de índole metafísica que he cometido, Vernengo me ve al final precipitarme irremediablemente, no en el infierno de la irracionalidad, que ya 
sería malo de por sí, sino en el del mismísimo «ser», que es con toda seguridad sima aún más profunda que aquélla, reservada a lo que parece para aquellos infames que osan hablar de derechos morales. No se sorprenda, sin embargo, el lector ante la desmesura de penalidades tamañas, pues bien merecidas las tiene, según Vernengo, quien cede a tan oscuras maquinaciones. Porque en realidad, aquel que lo hace no trata sólo de hacer una teoría de los derechos, o una descripción de los derechos humanos, o una presentación de sus caracteres, o una fundamentación de los mismos. Todo esto sería sólo el disfraz amable de una negra intención clandestina: ser vehículo nada más y nada menos que de la «voluntad de poder» y de su manifestación más notoria, como es la violencia institucionalizada. Y ya con las «cartas del juego» puestas al descubierto así por Vernengo, no le queda al reo más remedio que reconocer la culpa y gritar a los cuatro vientos que los derechos humanos han de volver, por mor de la tradición, al recinto del que aviesamente fueron sacados y en el que siempre habían vivido felizmente: el derecho positivo. Sobre todo, claro está, en Buenos Aires. 